\title{
Unravelling the silicon-silicon dioxide interface under different operating conditions
}

\author{
Shuai Nie ${ }^{1, *}$, Ruy Sebastian Bonilla ${ }^{2}$, Ziv Hameiri ${ }^{1}$ \\ ${ }^{1}$ School of Photovoltaic and Renewable Energy Engineering, University of New South Wales, Sydney, \\ NSW 2052, Australia \\ ${ }^{2}$ Department of Materials, University of Oxford, Oxford, OX1 3PH, United Kingdom \\ * Corresponding author: s.nie@student.unsw.edu.au
}

\begin{abstract}
Silicon dioxide $\left(\mathrm{SiO}_{2}\right)$ has played a critical role in the development of high-efficiency silicon (Si)-based photovoltaic devices. Recently, it has experienced a renaissance as an interlayer in many of the new contact passivating structures. Studies have extensively investigated the recombination process at the $\mathrm{Si}_{-} \mathrm{SiO}_{2}$ interface, however, only little is known about the impact of temperature on the surface recombination. In this study, we investigate the recombination at the $\mathrm{Si}_{-} \mathrm{SiO}_{2}$ interface by varying the temperature, excess carrier density, and dielectric fixed charge. An improved lifetime is observed with increasing temperature. A forming gas anneal is used to improve the passivation quality, however, at higher temperatures, the hydrogenated interface passivation degrades due to increased surface state density. The degradation is stronger for corona-charged $\mathrm{SiO}_{2}$, due to the instability of the corona charge within the dielectric. Using the extended Shockley-Read Hall recombination model, the $\mathrm{Si}_{-} \mathrm{SiO}_{2}$ interface defects' parameters are extracted. Most importantly, we determine the value and the temperature-dependence of the capture cross-sections at this interface.
\end{abstract}

Keywords: silicon dioxide; interface; surface passivation; corona charge; temperature-dependence

\section{INTRODUCTION}

The energy conversion efficiency of silicon ( $\mathrm{Si}$ ) solar cells strongly depends on carrier recombination in the bulk and at their surfaces [1]. Extensive effort has been devoted to the improvement of the bulk quality via refined control of the crystallization process [2], gettering [3], and hydrogenation [4]. Thus, the performance of many $\mathrm{Si}$ solar cells is now more sensitive to interface recombination [5]. Furthermore, as the current photovoltaics (PV) industry tends towards thinner Si substrates and higher cell performance [6], reducing interface recombination by surface passivation is extremely important [7].

The Si surface features an abrupt discontinuation of the crystal lattice, resulting in a significant density of states being present within the bandgap, leading to large surface recombination rates [8]. Surface passivation reduces this undesirable recombination [8]. This is commonly achieved by the combination of two approaches, referred to as 'chemical passivation' and 'field-effect passivation' [8]. As pointed out by Cuevas et al $[9,10]$, the term 'field-effect passivation' is misleading, as the electric field cannot repel excess minority carriers away from the surface, and instead modifies the surface carrier concentration to reduce recombination rates. Hence, this approach can be referred to as charge-assisted population control $[9,10]$. Chemical passivation is obtained by reducing the surface state density $\left(D_{i t}\right)$ and lowering the capture probabilities, while charge-assisted population control is achieved by the deposition of charge to reduce the concentration of one type of carriers available at the surface [8]. Often a dielectric layer is used to simultaneously reduce $D_{i t}$ and provide a fixed charge density $\left(Q_{f}\right)$ [8].
Silicon dioxide $\left(\mathrm{SiO}_{2}\right)$ is the first and most studied dielectric for surface passivation of Si [11]. It has played a key role in the development of $\mathrm{Si}$ photovoltaics, leading to the first $20 \%$ efficient Si solar cells [11,12]. Although the current industry standard surface passivation materials are silicon nitride $[13,14]$ and aluminum oxide [15], a thin $\mathrm{SiO}_{2}$ or silicon oxide $\left(\mathrm{SiO}_{\mathrm{x}}\right)$ film is often included in the stack to enhance the passivation quality $[11,16]$. Recently, $\mathrm{SiO}_{2}$ is experiencing a renaissance as an indispensable component for various types of passivating contacts $[10,11]$.

The electrical properties of the $\mathrm{Si}-\mathrm{SiO}_{2}$ interface, usually described by $D_{i t}, Q_{f}$, and the capture cross-sections for electrons and holes $\left(\sigma_{n}\right.$ and $\left.\sigma_{p}\right)$, have been studied extensively in the past [17-25]. A majority of the measurements have been performed on metal-oxide-semiconductor (MOS) structures using deep level transient spectroscopy (DLTS), and capacitance-voltage (CV) measurements [17-25]. A relatively low density of positive $Q_{f}$ (in the range of $10^{10}-10^{11} \mathrm{~cm}^{-2}$, depending on the process) has been reported in the as-grown $\mathrm{SiO}_{2}$ films $[8,11]$. Therefore, it appears that the passivation quality provided by $\mathrm{SiO}_{2}$ mainly relies on reducing $D_{i t}$. Although $D_{i t}$ strongly depends on the fabrication process [24], it seems to be above $10^{11} \mathrm{~cm}^{-2} \mathrm{eV}^{-1}$ for as-oxidized layers and can be further reduced by a forming gas anneal [8]. Extremely low $D_{i t}$, in the range of $10^{9} \mathrm{~cm}^{-2} \mathrm{eV}^{-1}$, have been achieved by a post-metallization annealing, often referred to as alneal [23]. Note that $D_{i t}$ has been found to be independent of the doping type and doping concentration of the silicon wafers, for doping concentrations below $10^{16} \mathrm{~cm}^{-3}$ [26]. Regarding $\sigma_{n}$ and $\sigma_{p}$, there is a large uncertainty of 1-2 orders of magnitude in their values as determined by DLTS measurements [8], [27]. However, most studies have found $\sigma_{n}$ to be larger than $\sigma_{p}[28,29]$. 
Depositing corona charge can enhance the passivation quality of $\mathrm{SiO}_{2}$ via population control [30][31]. The additional charge manipulates the surface potential and the interface band bending to reduce the surface recombination. Glunz et al. [32] used corona charge to study interface properties of $\mathrm{Si}_{-} \mathrm{SiO}_{2}$ on both lifetime structures and solar cells. They found that the surface recombination is significantly reduced when the dielectric is highly charged either with negative or positive $Q_{f}$, with better results being obtained for positive charge since $\sigma_{n}>$ $\sigma_{p}$. However, as the corona charge was not stable and dissipated with time, this method has not been utilized for industrial solar cells. Recently, Bonilla et al. [33] proposed a technique to stabilise the charge by a chemical treatment. Surface recombination velocity (SRV) below $7 \mathrm{~cm} / \mathrm{s}$ for three years with a decay time constant of 8.7 years has been demonstrated [33]. However, the stability of the charge has not been studied under realistic operating temperatures.

Despite the large amount of studies regarding the $\mathrm{Si}-\mathrm{SiO}_{2}$ interface, most of them provide information only at standard testing conditions (STC). Recent studies [34-37] have shown that it is increasingly necessary to characterize solar cells at various temperatures, as temperature has a critical impact on the electrical properties of the cell. Therefore, it is of utmost importance to study the temperature dependence of the $\mathrm{Si}_{-} \mathrm{SiO}_{2}$ interface properties to improve our predictions regarding the device performance under realistic operation conditions. In this study, we investigate the recombination at the $\mathrm{Si}_{-} \mathrm{SiO}_{2}$ interface under a wide range of variables, including temperature, excess carrier density $(\Delta n)$, and $Q_{f}$.

\section{EXPERIMENT}

\section{A. Sample preparation}

Phosphorus-doped, 4" $n$-type float zone (FZ) Si wafers (planar surfaces, crystal orientation [100]) with a resistivity of $1 \pm 0.1 \Omega . \mathrm{cm}$ and thickness of $200 \pm 10 \mu \mathrm{m}$ are used in this study to fabricate symmetrical lifetime structures. All wafers underwent a Radio Corporation of America cleaning before thermal dry oxidation at $1050{ }^{\circ} \mathrm{C}$, producing $100 \mathrm{~nm}$ thick $\mathrm{SiO}_{2}$ on both sides. A subset of the wafers received a forming gas $\left(5 \% \mathrm{H}_{2}\right.$ diluted in $\left.95 \% \mathrm{~N}_{2}\right)$ annealing (FGA) at $425^{\circ} \mathrm{C}$ for 25 minutes. Chemical treatment was then used to produce a $\mathrm{SiO}_{2}$ hydrophobic surface and thus, stabilize the corona charge as reported in $[33,38]$. Each wafer was then cleaved into four tokens. Corona charge was deposited using a custom-built corona discharge setup with a point-to-plane configuration [33] on three tokens from each wafer (from both FGA and non-FGA groups) with charging time (CT) of 10, 20 and $40 \mathrm{sec}$. The corona rig used $30 \mathrm{kV}$ applied to the point electrode, which stood at a distance of $20 \mathrm{~cm}$ from the sample. It is noted that the bulk defects reported in [39], that may exist in high-quality FZ wafers, were eliminated by the thermal oxidation process.

\section{B. Characterization setup}

A modified lifetime tester [40] based on the Sinton WCT-120 instrument is used in this study. In particular, a cryostat is used to vary the sample temperature in the range of $223 \mathrm{~K}$ to $473 \mathrm{~K}$. Moreover, the system is equipped with two different light sources, a Xenon flash and an $810 \mathrm{~nm}$ light-emitting diode (LED) to allow a lifetime measurement under a wide injection level range. The photoconductance-based injection dependent effective lifetime $\left(\tau_{\text {eff }}\right)$ is measured using both the quasi-steadystate (QSS) [41] and transient modes in the temperature range from $223 \mathrm{~K}$ to $473 \mathrm{~K}$. The generation rate is calibrated by comparing the QSS and transient measurements at each temperature (in the $\Delta n$ range around $10^{15}-10^{16} \mathrm{~cm}^{-3}$ ). The temperature-dependent carrier mobility model of Klaassen et al. [42] is used to calculate $\Delta n$.

\section{MODELLING}

\section{A. Surface recombination}

To gain insights into the recombination mechanisms at the $\mathrm{Si}-\mathrm{SiO}_{2}$ interface under different operating conditions, the extended Shockley-Read-Hall (SRH) formalism, first introduced by Grove and Fitzgerald [43] and later improved by Girisch et al. [28], Aberle et al. [29] and Bonilla et al. [44] is used. The surface recombination $\left(U_{s}\right)$ is described by a distribution of interface states:

$$
U_{s}=\int_{E_{v}}^{E_{c}} \frac{\left(n_{s} p_{s}-n_{i}^{2}\right)}{\frac{\left[n_{s}+n_{1}(E)\right]}{v_{t h p} D_{i t}(E) \sigma_{p}}+\frac{\left[p_{s}+p_{1}(E)\right]}{v_{t h n} D_{i t}(E) \sigma_{n}}} d E
$$

$$
n_{1}=n_{i} \exp \left(\frac{E_{t}-E_{i}}{k_{B} T}\right), \quad p_{1}=n_{i} \exp \left(\frac{E_{i}-E_{t}}{k_{B} T}\right)
$$

where $n_{i}$ is the $\mathrm{Si}$ intrinsic carrier concentration [45], $v_{t h p}\left(v_{t h n}\right)$ is the thermal velocity of hole (electron) $[46,47], E_{t}$ is the defect energy level, $E_{i}$ is the intrinsic Fermi level, $k_{B}$ is the Boltzmann constant, $T$ is the temperature, and $n_{s}$ and $p_{s}$ are the carrier concentrations at the surface defined as

$$
\begin{gathered}
n_{s}=\left(n_{0}+\Delta n\right) \exp \left(\frac{q \Psi_{s}}{k_{B} T}\right) \\
p_{s}=\left(p_{0}+\Delta n\right) \exp \left(-\frac{q \Psi_{s}}{k_{B} T}\right)
\end{gathered}
$$

where $n_{0}\left(p_{0}\right)$ is the equilibrium electron (hole) concentration and $\Psi_{s}$ is the surface potential. The exact solution of $\Psi_{s}$ requires solving the Poisson and continuity equations for electrons and holes dynamics imposed by the surface properties and the operating conditions [8]. As proposed by Girisch et al. [28], $\Psi_{s}$ can be solved using an iterative approach assuming constant quasi-Fermi energy levels throughout the surface space charge region. This approach is based on the charge neutrality: 


$$
Q_{S i}+Q_{i t}+Q_{f}+Q_{g}=0
$$

where $Q_{S i}$ is the charge induced in the silicon, $Q_{i t}$ is the charge in the surface defect states, $Q_{f}$ is the fixed charge in the dielectric layer, and $Q_{g}$ is the charge induced in the gate electrode (not relevant for this study). More information regarding these methods can be found in $[28,29,44]$.

\section{B. Modelling procedure}

In this section, we present the method used to determine the interface defects' parameters by temperature- and injectiondependent lifetime spectroscopy (TIDLS). The method is based on previous frameworks $[28,29,44]$ and has been extended to take the temperature dependence into consideration.

The experimentally obtained $\tau_{\text {eff }}$ can be expressed as:

$$
\frac{1}{\tau_{\text {eff }}}=\frac{1}{\tau_{s}}+\frac{1}{\tau_{\text {Aug }}}+\frac{1}{\tau_{\text {Rad }}}+\frac{1}{\tau_{\text {SRHbulk }}}
$$

where $\tau_{s} \tau_{A u g}, \tau_{\text {Rad }}$, and $\tau_{\text {SRHbulk }}$ represent the surface, Auger [48], radiative [49,50] and SRH bulk [51,52] lifetimes, respectively. It is noted that $\tau_{\text {eff }}$ quantifies the recombination occurring simultaneously within the bulk and at the surfaces. It is challenging to obtain $\tau_{\mathrm{SRH} \text { bulk }}$ and $\tau_{s}$ from the measured $\tau_{\text {eff. }}$. As will be shown below, comparing the same wafers with and without corona charge allows us to confirm that $\tau_{\text {eff }}$ of the noncharged samples is dominated by the surface recombination ( $\tau_{\text {bulk }}$ of the used wafers is above $3 \mathrm{~ms}$ ). Hence, for the uncharged samples, it can be assumed (with a relative error $<2 \%$ for the non-FGA wafers and $<6 \%$ for the FGA wafers) that:

$$
\frac{1}{\tau_{\text {eff }}} \approx \frac{1}{\tau_{s}}+\frac{1}{\tau_{\text {Aug }}}+\frac{1}{\tau_{\text {Rad }}}
$$

To extract the interface parameters, $\tau_{s}$ are fitted using the SRH recombination model and the formalism proposed by Girisch et al. [28] to determine $\Psi_{s}$ for any combination of $D_{i t}$, $Q_{f}, \sigma_{n}$ and $\sigma_{p}$. Here we assume $D_{i t}$ to be temperatureindependent but energy-dependent, as the band tail states are critical for determining the surface potential [53]. The energy dependence is described by [44]:

$$
D_{i t}(E)=D_{i t_{-} m g}+D_{i t_{-} C} e^{m_{C} E+E_{0 C}}+D_{i t_{-} V} e^{m_{V} E+E_{0 V}}
$$

where $D_{i t} m g$ is the density of states at the middle of the band gap, $m_{C}\left(m_{V}\right)$ and $E_{O C}\left(E_{O V}\right)$ determine the rate that the tail of states approaches $D_{i t_{-} C}\left(D_{i t_{-} V}\right)$ at the conduction (valence) band edge.

Constant capture cross-sections over the bandgap are assumed since: (a) it has been demonstrated that the capture cross-sections are only weakly dependent on the energy [25,54,55], (b) Bonilla et al. [44] shows that the surface recombination is insensitive to the energy dependence of surface recombination velocity of electrons and holes $\left(S_{n}=v_{t h n} D_{i t} \sigma_{n}\right.$ and $\left.S_{p}=v_{t h p} D_{i t} \sigma_{p}\right)$, particularly when most of the recombination activity is mediated by deep-level defects, (c) previous studies have demonstrated that it is not required to include the energy dependence of the capture cross-sections into the model [56,57]. The capture cross-sections' temperature dependence is considered using [58]:

$$
\sigma_{n / p}=\sigma_{n 0 / p 0} \exp \left(-E_{\infty} / k T\right)
$$

where $\sigma_{n 0}\left(\sigma_{p 0}\right)$ are the temperature-independent pre-factors of capture cross-section of electron (hole) and $E_{\infty}$ is the thermal barrier that a free electron in the conduction band has to overcome to be captured by the defect level. This temperature dependence is further discussed in Section IV-C.

We use the intrinsic lifetime parameterization proposed by Richter et al. [48], while the radiative recombination coefficient is taken from $[49,50]$. Note that the temperature dependence of all the parameters in the intrinsic lifetime model [48] has been considered in this study, except for the temperature dependence of the Auger coefficients. Although Wang and MacDonald [59] have evaluated the ambipolar Auger coefficient at different temperatures ( $243 \mathrm{~K}$ to $473 \mathrm{~K}$ ), their parameterization is valid only for the very high $\Delta n$ of $5 \times 10^{16} \mathrm{~cm}^{-3}$ and is not suitable for the samples investigated here. Since temperature independent Auger coefficients are assumed, discrepancy is expected to be larger at high $\Delta n$. Note that a recent study [60] has demonstrated measured lifetimes that are higher than the intrinsic lifetime limit [48], indicating the urgent need to update the intrinsic model and to extend it to a wider range of temperatures.

The fit quality is evaluated using the residual:

$$
\begin{gathered}
\text { Residual }=\sum_{i=1}^{i} \sum_{j=1}^{j}\left(1-\frac{\tau_{\text {fitted }_{i, j}}}{\tau_{\text {measured }_{i, j}}}\right)^{2} \\
\tau_{i, j}=\tau\left(\Delta n_{i}, T_{j}\right)
\end{gathered}
$$

where $\tau_{\text {fitted }}$ is obtained from the discussed fitting procedure and $\tau_{\text {measured }}$ is the experimentally obtained $\tau_{\text {eff. }}$. The number of measured temperatures is represented by $j$, while $i$ is the number of $\Delta n$ points where the fit is evaluated.

Inspired by the defect parameter solution surface (DPSS) procedure [61], the values of $\sigma_{n 0}$ and $Q_{f}$ are fixed, while the other parameters $\left(\sigma_{p 0}, E_{\infty}, D_{i t}\right.$ in the middle of the band gap and band tails) are fitted and the fit quality is recorded. By sweeping $\sigma_{n 0}$ and $Q_{f}$ across the expected range of values and repeating the fitting, parameter sets that provide low fitting residual are identified. This procedure provides not only the interface defect parameters, but also the associated uncertainty by calculating the standard deviation of all the sets of fitting parameters that provide relatively good fits and low residual values $(<0.9)$. An example of a residual map and more details are provided in Appendix A.

For corona-charged wafers, the assumption that $\tau_{\text {eff }}$ is dominated by the surface recombination is no longer valid. The temperature- and injection-dependent $\tau_{\mathrm{SRH} \text { bulk }}$ impacts $\tau_{\text {eff }}$, especially when $\tau_{s}$ is large (as for highly charged dielectrics). 
To eliminate the impact of $\tau_{\mathrm{SRH} b u l k}$, the lifetime difference $\left(\Delta \tau_{\text {charge }}\right)$ between charged and uncharged wafers is calculated:

$$
\Delta \tau_{\text {charge }}=\frac{1}{\frac{1}{\tau_{\text {uncharged }}}-\frac{1}{\tau_{\text {charged }}}}
$$

where $\tau_{\text {uncharged }}$ ( $\left.\tau_{\text {charged }}\right)$ is the measured lifetime of the uncharged (charged) wafer interpolated to the same $\Delta n$. Here, it is assumed that $\Delta \tau_{\text {charge }}$ represents variation in $\tau_{s}$ due to the increase of $Q_{f}$, while $D_{i t}, \sigma_{n}$ and $\sigma_{p}$ are considered to remain unchanged during the corona charge deposition [38,62]. Furthermore, $\tau_{\mathrm{SRH} \text { bulk }}$ of charged and uncharged samples are assumed to be identical, as these samples originate from the same wafer. $\Delta \tau_{\text {charge }}$ is then fitted by the modelled $\tau_{s}$ difference by varying $Q_{f}$.

In many cases, the decrease in recombination occurring at the $\mathrm{Si}_{-} \mathrm{SiO}_{2}$ interface from corona charge reaches a plateau, in contradiction to theoretical expectations [32]. Glunz et al. [32] suggested surface potential fluctuations, originating from the inhomogeneous corona charge distribution, to explain this deviation between measurements and theory. Recently, Bonilla et al. [63] demonstrated that using a 'charge fluctuations' model rather than surface potential fluctuations, provides a better fit. Although considered in this study, we did not include spatial fluctuations of the surface charge (or potential) since the polished wafers (both uncharged and charged samples) demonstrate uniform photoluminescence images and as the sensed region in the modified lifetime system is smaller than the standard system (with a radius of $7 \mathrm{~mm}$ ).

\section{RESULTS AND DISCUSSION}

\section{A. Temperature- and injection- dependent lifetime measurements}

Figure 1 shows TIDLS measurements of five representative wafers passivated with (a) $\mathrm{SiO}_{2}$, (b) $\mathrm{SiO}_{2}+\mathrm{FGA}$, (c) $\mathrm{SiO}_{2}+$ $\mathrm{FGA}+$ corona charge $(10 \mathrm{sec}),(\mathrm{d}) \mathrm{SiO}_{2}+\mathrm{FGA}+$ corona charge $(20 \mathrm{sec})$, and (e) $\mathrm{SiO}_{2}+\mathrm{FGA}+$ corona charge (40 sec) acquired as the temperature increases from $223 \mathrm{~K}$ to $473 \mathrm{~K}$. Two methods are used for the presentation of $\tau_{\text {eff: }}$ different scales of the $\mathrm{z}$-axis are used to optimise the display of each individual figure, while the same colour scale is used to clearly demonstrate the different values. Across the entire temperature range, $\tau_{\text {eff }}$ of the wafer passivated with $\mathrm{SiO}_{2}+\mathrm{FGA}$ is higher than $\tau_{\text {eff }}$ of the wafer passivated with only $\mathrm{SiO}_{2}$. As FGA leads to hydrogen passivation of the interface dangling Si bonds, $D_{i t}$ is expected to be reduced after this process [8].

The effectiveness of corona charge for improving the passivation quality of $\mathrm{SiO}_{2}$ is clearly demonstrated in Figs. 1c-e. A significant increase of $\tau_{\text {eff }}$, by more than one order of magnitude, is observed after the corona charge deposition. An outstanding $\tau_{\text {eff }}$ above $4 \mathrm{~ms}$ at $\Delta n$ of $1 \times 10^{15} \mathrm{~cm}^{-3}$ (at room temperature) is achieved after $40 \mathrm{sec}$ of corona charging. The improvement due to the additional charge is more noticeable at low $\Delta n$ as $\tau_{\text {eff }}$ at higher $\Delta n$ is dominated by Auger recombination.

As illustrated in Figs. 1a and 1b, wafers without corona charge show a complex temperature dependency. At low temperatures $(223 \mathrm{~K}-303 \mathrm{~K}), \tau_{\text {eff }}$ is found to decrease with increasing temperature at high to medium $\Delta n$, whereas the opposite trend is observed at low $\Delta n$. At higher temperatures $(303 \mathrm{~K}-473 \mathrm{~K}), \tau_{\text {eff }}$ increases with increasing temperature for the entire $\Delta n$ range. However, it is noticeable that $\tau_{\text {eff }}$ of the wafer passivated with $\mathrm{SiO}_{2}+\mathrm{FGA}$ drops at temperatures above $373 \mathrm{~K}$, as indicated by an arrow in Fig. 1b. This is probably due to $\tau_{s}$ degradation at high temperatures, in particular due to the instability of the interface hydrogen passivation. This is evidenced by the reduction of $\tau_{\text {eff }}$ remeasured at $303 \mathrm{~K}$ after the high-temperature measurements (not shown here). The thermal instability of the $\mathrm{Si}-\mathrm{H}$ bonds has also been observed by others [64]. Note that no variation of $\tau_{\text {eff }}$ occurs after the completion of the temperature scan of the $\mathrm{SiO}_{2}$-only passivated wafer, indicating that the observed change in the FGA-passivated sample is not due to the loss of $Q_{f}$ or bulk degradation.

In contrast to the uncharged wafers, all the charged wafers show a consistent temperature behavior for low to moderate temperatures, where $\tau_{\text {eff }}$ is found to improve with increasing temperature for the entire $\Delta n$ range. This temperature dependence appears to be much stronger at low $\Delta n$. However, the change of $\tau_{\text {eff }}$ is not monotonic at higher temperatures, where a 'valley' (indicated by arrows) is observed in Figs. 1c-e. We assign it to the degradation of the interface hydrogen passivation (as discussed before), as well as the leakage of corona charge at high temperatures (as will be discussed in Section IV-B). Since the hydrogen-induced passivation degrades and corona charge leaks at high temperatures, $\tau_{\text {eff }}$ is expected to drop continuously with increasing temperature. However, it is interesting to note that $\tau_{\text {eff }}$ recovers and then peaks at the highest measured temperature of $473 \mathrm{~K}$ (Figs. 1b-e). This could be explained by a trade-off between the reduced recombination activity of the interface defect at higher temperatures (as will be discussed in Section IV-C) and the increase of $D_{i t}$ and reduction of $Q_{f}$ at the same temperature range.

\section{B. Stability of hydrogen passivation and corona charge at high temperatures}

In this section, the impact of high temperatures on the $\mathrm{SiO}_{2}$ passivation quality is investigated. Wafers are dark annealed at different temperatures and monitored by in-situ lifetime measurements using a Sinton WCT-120TS lifetime tester. Fig. 2 shows the normalized $\tau_{\text {eff }}$ obtained at $\Delta n$ of $1 \times 10^{15} \mathrm{~cm}^{-3}$ as a function of dark annealing duration at $373 \mathrm{~K}$. The initial lifetime $\left(\tau_{0}\right)$ of each wafer at $373 \mathrm{~K}$ is given in the figure's caption. 

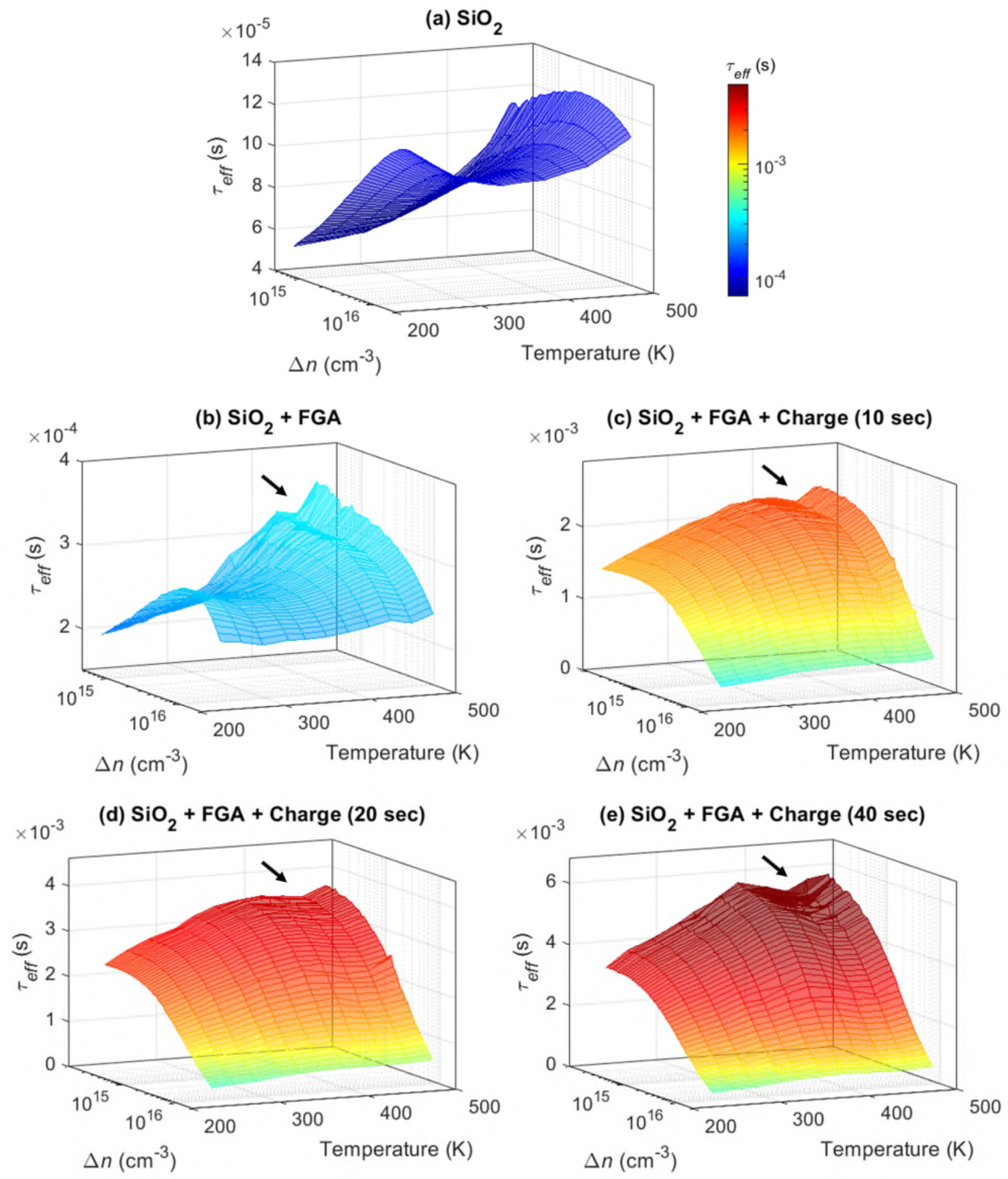

Fig. 1. Temperature and injection dependent $\tau_{\text {eff }}$ for $n$-type $\mathrm{Si}$ wafers passivated with (a) $\mathrm{SiO}_{2}$, (b) $\mathrm{SiO}_{2}+\mathrm{FGA}$, (c) $\mathrm{SiO}_{2}+\mathrm{FGA}+$ corona charge $(10 \mathrm{sec} \mathrm{CT}),(\mathrm{d}) \mathrm{SiO}_{2}+\mathrm{FGA}+$ corona charge $(20 \mathrm{sec} \mathrm{CT})$, and (e) $\mathrm{SiO}_{2}+\mathrm{FGA}+$ corona charge $(40 \mathrm{sec} \mathrm{CT})$. 
No clear change in $\tau_{\text {eff }}$ can be observed for the wafer passivated with only $\mathrm{SiO}_{2}$, indicating that: (1) the intrinsic oxide charge is stable at these temperatures, (2) no degradation in the chemical passivation quality (obtained without FGA) occurs at high temperatures, and (3) the bulk lifetime $\left(\tau_{\text {bulk }}\right)$ does not degrade. The last point has also been confirmed by similar $\tau_{\text {eff }}$ measured for both annealed and un-annealed samples after $10 \mathrm{sec}$ deposition of corona charge.

While examining the wafer that is passivated with $\mathrm{SiO}_{2}$ and corona charge (40 sec without FGA), a degradation is observed (in the range of 10\%), indicating a loss of charge at high temperatures. Worsening of the chemical passivation quality or the bulk quality is less likely as it has not been observed for the $\mathrm{SiO}_{2}$-passivated wafer.

A decrease of up to $5 \%$ of $\tau_{\text {eff }}$ is observed during the dark annealing for the wafer passivated by $\mathrm{SiO}_{2}+\mathrm{FGA}$. We assign this change of $\tau_{\text {eff }}$ to the instability of hydrogen passivation at high temperatures that increases $D_{i t}$ and thus, increases surface recombination. It seems that the thermal instability of the corona charge at high temperatures has a stronger impact on the degradation compared to the instability of the hydrogen passivation.

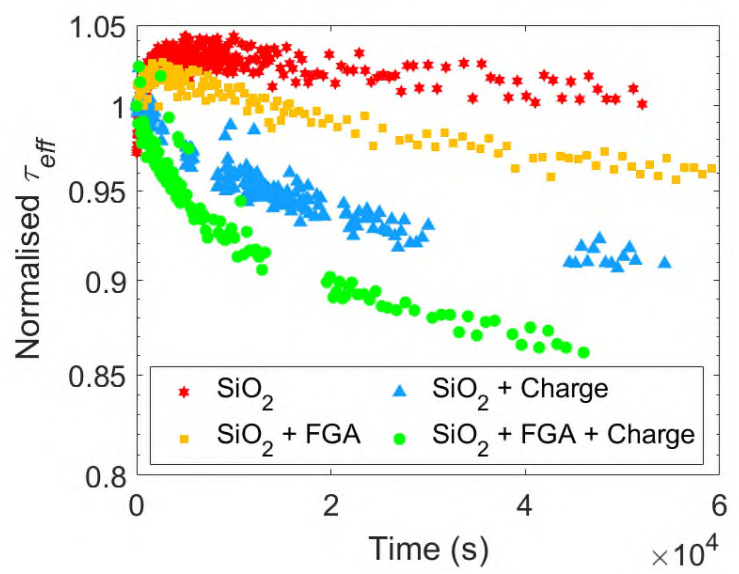

Fig. 2. Evolution of $\tau_{e f f}$ as a function of the dark annealing (at 373 K) time for different wafers. $\tau_{0}$ are $78 \pm 3,3150 \pm 126,301 \pm 12$, $5755 \pm 230 \mu$ s for wafers passivated with $\mathrm{SiO}_{2}, \mathrm{SiO}_{2}+$ charge (40 sec $\mathrm{CT}), \mathrm{SiO}_{2}+\mathrm{FGA}$ and $\mathrm{SiO}_{2}+\mathrm{FGA}+$ charge $(40 \mathrm{sec} \mathrm{CT})$, respectively.

As expected, the fastest degradation rate with the highest degradation extent is obtained for the wafer passivated with $\mathrm{SiO}_{2}+\mathrm{FGA}+$ corona charge $(40 \mathrm{sec})$, as it combines two instability mechanisms.

Figure 3 displays the evolution of the normalized $\tau_{\text {eff }}$ (extracted at $\Delta n$ of $1 \times 10^{15} \mathrm{~cm}^{-3}$ ) for wafers passivated with $\mathrm{SiO}_{2}$ + FGA + corona charge $(40 \mathrm{sec})$ under dark annealing at different temperatures. No significant degradation is observed at $323 \mathrm{~K}$. The degradation extent is found to increase with increasing temperature. Moreover, the degradation rate shows a strong temperature dependence where a faster degradation rate is observed at high temperatures. A similar observation is made on all the corona-charged wafers (not shown here).

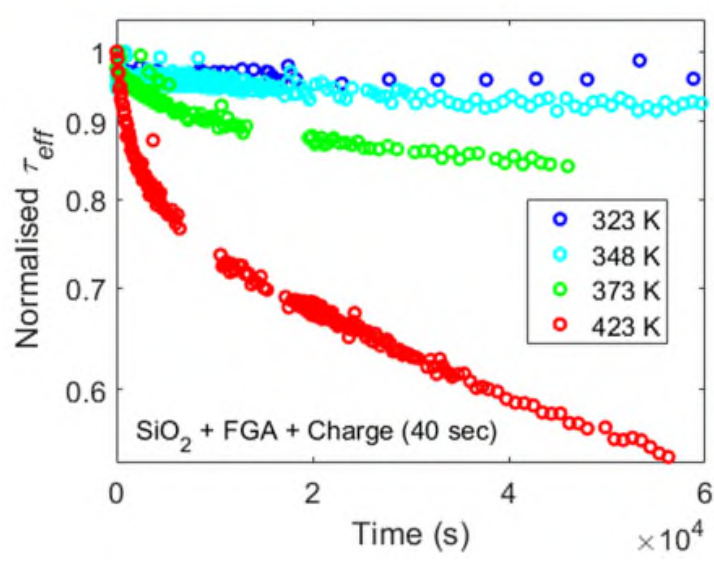

Fig. 3. Evolution of $\tau_{e f f}$ for wafers passivated with $\mathrm{SiO}_{2}+\mathrm{FGA}+$ corona charge (40 sec CT) under dark annealing at different temperatures. $\tau_{0}$ are $4303 \pm 172,4627 \pm 185,5755 \pm 230,6188 \pm 247 \mu$ s at $323,348,373$ and $423 \mathrm{~K}$, respectively.

\section{Modelling lifetime measurements}

To extract the electrical parameters of the $\mathrm{Si}-\mathrm{SiO}_{2}$ interface defects, the TIDLS measurements of the wafer passivated with only $\mathrm{SiO}_{2}$ are fitted using the method introduced in Section III. Fig. 4 presents both measured and simulated temperaturedependent $\tau_{\text {eff. }}$ The black error bars represent the measurement uncertainty calculated as the sum of the different uncertainties associated with lifetime measurements [65]. For visibility reasons, the error bars are shown only for representative injection levels and temperature. A great fit is obtained for all the temperatures. From the fit, the $\mathrm{Si}-\mathrm{SiO}_{2}$ interface defect parameters are determined to be: $Q_{f}=(1 \pm 0.5) \times 10^{10} \mathrm{q} / \mathrm{cm}^{2}, D_{i t}$ $=(1.3 \pm 0.2) \times 10^{11},(2.1 \pm 1.4) \times 10^{15},(2.6 \pm 1.8) \times 10^{15} \mathrm{~cm}^{-2} \mathrm{eV}^{-1}$ for the middle of the band gap, valence band and conduction band, $\sigma_{n}=(2 \pm 0.4) \times 10^{-16} \exp \left[(-10 \pm 1) \times 10^{-3} / \mathrm{kT}\right] \mathrm{cm}^{2}$ and $\sigma_{p}=$ $(1 \pm 0.4) \times 10^{-16} \exp \left[(-10 \pm 1) \times 10^{-3} / \mathrm{kT}\right] \quad \mathrm{cm}^{2}$. A comparison between the interface defects' parameters obtained from this study and literature values will be discussed below.

Please note that the lifetime measurements in this study are not affected by the edges of the wafers. The size of the wafers was selected such that the edges are at least three diffusion lengths long (considering the maximum estimated diffusion length) from the photoconductance coil sensing area (of a radius of $7 \mathrm{~mm}$ ).

The experimental data could not be satisfactorily reproduced if temperature-dependence of the capture cross-section is not considered. In this study, the lattice relaxation multi-phonon emission model [58] is used to describe the temperature dependence of $\sigma_{n}$ and $\sigma_{p}$. A similar dependence has been suggested in the past for the interfaces of MOS devices [21], [55]. However, the determined values $\left[\sigma_{n 0}=(2 \pm 0.4) \times 10^{-16} \mathrm{~cm}^{2}\right.$ and $\left.E_{\infty}=(10 \pm 1) \mathrm{meV}\right]$ are lower compared to the values obtained from DLTS measurements of the MOS devices $\left(\sigma_{n 0}=\right.$ $9 \times 10^{-14} \mathrm{~cm}^{2}$ and $E_{\infty}=89 \mathrm{meV}$ ) [55]. The difference between 
the values can be explained by the different surface conditions, for example, the epitaxial silicon wafers in [55] compared to polished FZ wafers, or the oxide growth and post-oxidation annealing process. It is interesting to note that the determined factors are within the same range of the capture cross-sections of bulk defects [61]. The finding regarding the temperature dependence of the capture cross-sections could also be relevant to other $\mathrm{Si}-\mathrm{SiO}_{2}$ interfaces, including tunneling oxides. Despite different oxide growth conditions and post-growth annealing, previous studies reported similar $\mathrm{Si}_{-} \mathrm{SiO}_{2}$ interface defect structural properties of thermally grown oxide, native oxide as well as oxides grown by wet chemistry [24,66-68]. These findings may indicate that the fundamental temperature dependence can be similar for the same defect group, although the growth conditions are different.

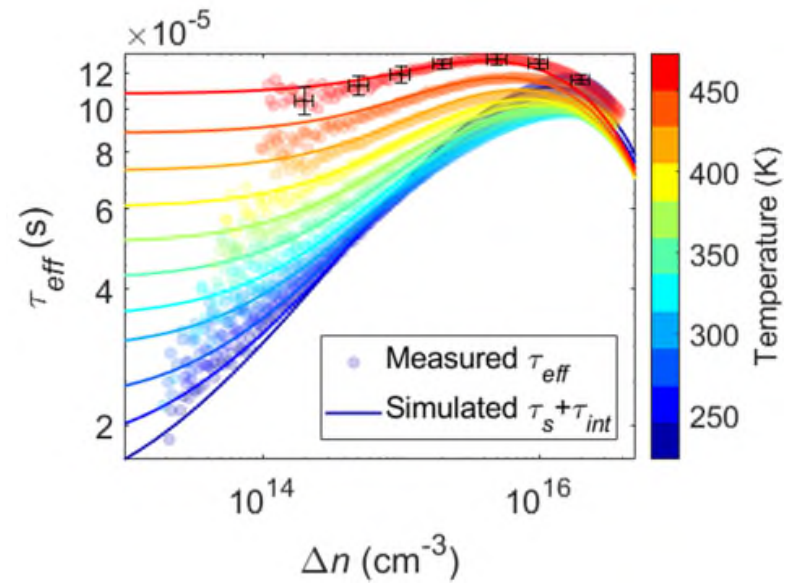

Fig. 4. Measured (symbol) and simulated (solid line) temperature and injection dependent $\tau_{\text {eff }}$ for wafers passivated with $\mathrm{SiO}_{2}$.

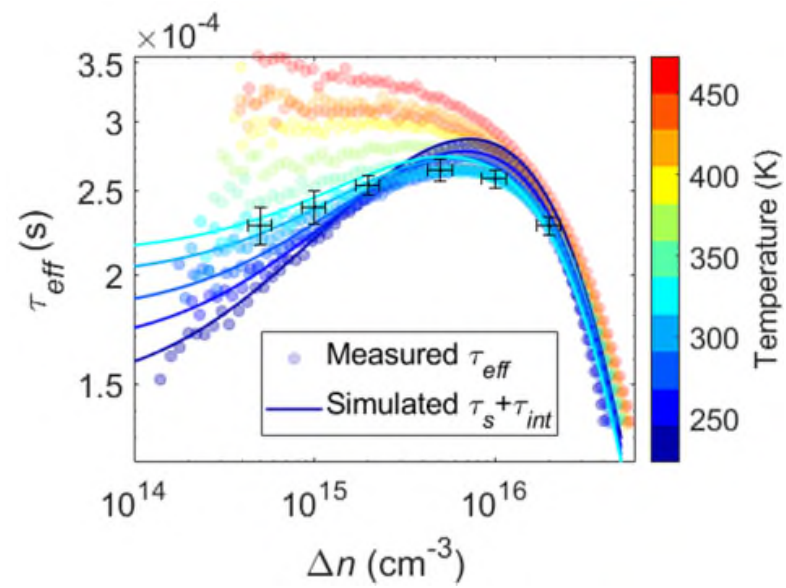

Fig. 5. Measured (symbol) and simulated (solid line) temperature and injection dependent $\tau_{\text {eff }}$ for wafers passivated with $\mathrm{SiO}_{2}+$ FGA.

At this stage, the same temperature dependence is assumed for both $\sigma_{p}$ and $\sigma_{n}$. As these parameters are only rarely measured, we cannot confirm this assumption, except for the good fit obtained. Further investigation is required to clarify this hypothesis.

To verify the model results, $\tau_{\text {eff }}$ measurements of the wafer passivated with $\mathrm{SiO}_{2}+$ FGA are fitted using the obtained set of interface parameters, modifying only $D_{i t}$ that was assumed to be changed by the FGA process. Since the hydrogen passivation is not stable at high temperatures (Section IV-B), the fits are done in the temperature range from $223 \mathrm{~K}$ to $323 \mathrm{~K}$ (no change of $\tau_{\text {eff }}$ has been observed within this temperature range for the measurement duration). The great agreement between measurements and fitting (see Fig. 5) confirms our previous conclusions and indicates that $D_{i t}$ has been reduced to $(4.5 \pm 1) \times 10^{10} \mathrm{~cm}^{-2} \mathrm{eV}^{-1}$ for the middle of the band gap $\left[(7.0 \pm 1.4) \times 10^{14}\right.$ for the valence band and $(1.6 \pm 0.6) \times 10^{15} \mathrm{~cm}^{-}$ ${ }^{2} \mathrm{eV}^{-1}$ for the conduction band] after the FGA process. Note that these values are insensitive to the small variations in $Q_{f}$. The extracted parameters are still within the given uncertainty, when $Q_{f}$ varies by $30 \%$, and are similar to previous reports (see Table I).

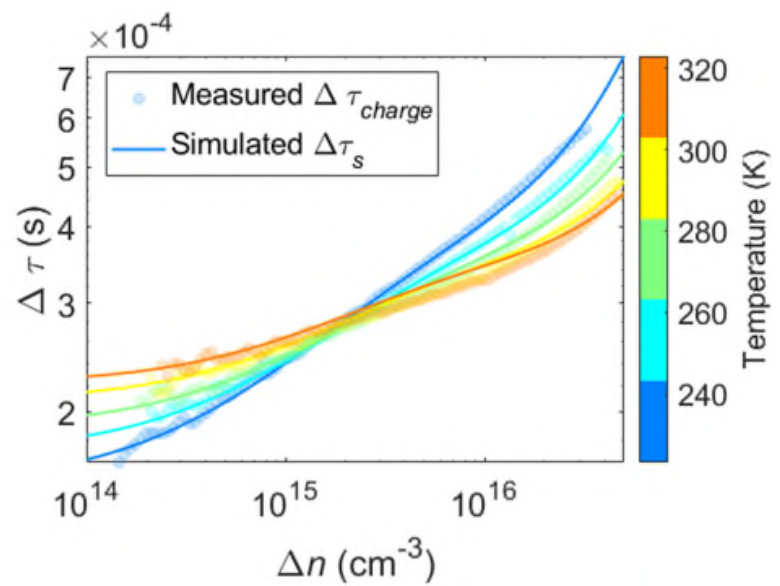

Fig. 6. Measured (symbol) and fitted (solid line) lifetime difference between charge $\left[\mathrm{SiO}_{2}+\mathrm{FGA}+\right.$ Corona Charge $\left.(20 \mathrm{sec} \mathrm{CT})\right]$ and uncharged $\left[\mathrm{SiO}_{2}+\mathrm{FGA}\right]$ wafers.

These interface parameters are used to fit the corona-charged wafers. As discussed in Section III-B, for charged wafers $\Delta \tau_{\text {charge }}$ is fitted to extract $Q_{f}$ (all the other parameters are fixed and assumed similar to the $\mathrm{SiO}_{2}+$ FGA case). An example of the fitting results is given in Fig. 6 for the wafer passivated with $\mathrm{SiO}_{2}+\mathrm{FGA}+$ Corona Charge $(20 \mathrm{sec})$. As can be seen, a good fit is obtained for the temperature range from $223 \mathrm{~K}$ to $323 \mathrm{~K}$. A similar fitting procedure has been carried out for the other corona-charged wafers. We determine a $Q_{f}$ of $(2.8 \pm 0.1) \times 10^{11}$, $(5.2 \pm 0.3) \times 10^{11}$ and $(1.2 \pm 0.2) \times 10^{12} \mathrm{q} / \mathrm{cm}^{2}$ for $10,20,40 \mathrm{sec} \mathrm{CT}$, respectively. These values agree well with the estimated charge deposition rate in the range of $10^{11} \mathrm{q} / \mathrm{sec}$, as previously reported [33,69]. 
Table I. Interface defects' parameters used to fit empirical data in this study and parameters from previous reports.

\begin{tabular}{|c|c|c|c|c|c|}
\hline & & $\mathrm{Q}_{\mathrm{f}}\left(\mathrm{q} / \mathrm{cm}^{2}\right)$ & $\mathrm{D}_{\mathrm{it} \_\mathrm{mg}}\left(\mathrm{cm}^{-2} \mathrm{eV}^{-1}\right)$ & $\sigma_{\mathrm{n}}\left(\mathrm{cm}^{2}\right)$ & $\mathrm{k}\left(\sigma_{\mathrm{n}} / \sigma_{\mathrm{p}}\right)$ \\
\hline This study & $n$-type $+\mathrm{SiO}_{2}$ & $(1 \pm 0.5) \times 10^{10}$ & $(1.3 \pm 0.2) \times 10^{11}$ & $(1.4 \pm 0.4) \times 10^{-16}$ at $300 \mathrm{~K}$ & $2 \pm 0.4$ \\
\hline Bonilla et al. ${ }^{\mathrm{a}}$ & $n$-type $+\mathrm{SiO}_{2}$ & $2.2 \times 10^{11}$ & $1 \times 10^{11}$ & $8.7 \times 10^{-16}$ & 7.9 \\
\hline Haug et al. ${ }^{\mathrm{b}}$ & $n$-type $+\mathrm{SiO}_{2}$ & $(2.4-2.6) \times 10^{11}$ & $1.2 \times 10^{11}$ & $7.5 \times 10^{-15}$ & 2.3 \\
\hline This study & $n$-type $+\mathrm{SiO}_{2}+$ FGA & $(1 \pm 0.5) \times 10^{10}$ & $(4.5 \pm 1) \times 10^{10}$ & $(1.4 \pm 0.4) \times 10^{-16}$ at $300 \mathrm{~K}$ & $2 \pm 0.4$ \\
\hline Bonilla et $a l .^{\mathrm{a}}$ & $n$-type $+\mathrm{SiO}_{2}+\mathrm{FGA}$ & $2.2 \times 10^{11}$ & $5 \times 10^{10}$ & $7.7 \times 10^{-16}$ & 13.4 \\
\hline Haug et al. ${ }^{\mathrm{b}}$ & $p$-type $+\mathrm{SiO}_{2}+\mathrm{FGA}$ & $(2.7-3) \times 10^{11}$ & $2.6 \times 10^{10}$ & $1.5 \times 10^{-14}$ & 5.2 \\
\hline Aberle et al..$^{\mathrm{c}}$ & $\begin{array}{l}\mathrm{SiO}_{2}+\text { post- } \\
\text { metallization anneal }\end{array}$ & $(6-8) \times 10^{10}$ & $(3-5) \times 10^{9}$ & - & $50-70$ \\
\hline Choi et al. ${ }^{\mathrm{d}}$ & $\begin{array}{l}n \text {-type }+ \text { p-doped poly- } \\
\mathrm{Si} / \mathrm{SiO}_{2} / \mathrm{c}-\mathrm{Si}\end{array}$ & $2.4 \times 10^{12}$ & $1 \times 10^{11}$ & $5 \times 10^{-15}$ & 1 \\
\hline
\end{tabular}

${ }^{a}$ [63]: Room temperature photoconductance decay measurements (the surface carrier population of silicon wafer are controlled during measurement by using a semi-transparent PEDOT:PSS gate).

${ }^{\mathrm{b}}$ [56]: Room temperature photoluminescence imaging with applied bias over the rear side passivation layer.

${ }^{\mathrm{c}}$ [23]: DLTS and CV measurements on MOS samples.

d [70]: Room temperature photoconductance decay measurements and CV measurements.

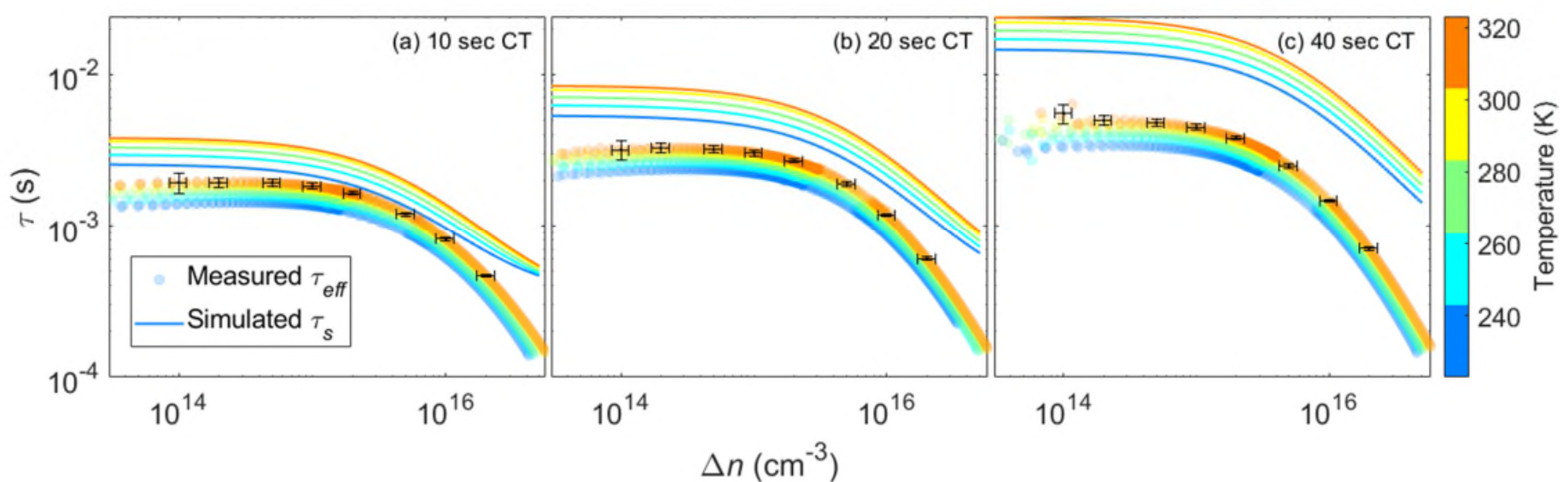

Fig. 7. Measured (symbol) $\tau_{\text {eff }}$ and simulated (solid line) $\tau_{s}$ for corona charged wafers with different CT (a) $10 \mathrm{sec}$ (b) $20 \mathrm{sec}$ and (c) $40 \mathrm{sec}$.

Figure 7 compares the measured $\tau_{\text {eff }}$ (symbol) and simulated $\tau_{s}$ (line) based on the interface defects' parameters obtained from the best fit for the charged wafers. It is interesting to note that $\tau_{s}$ of the charged wafers increases with increasing temperature. Hence, the surface recombination decreases at higher temperatures, despite the increase of the capture-cross sections. This is due to the increasing surface potential with rising temperature, resulting in increased $n_{s}$ and reduced $p_{s}$ (Eq. $3)$. Therefore, the surface recombination is expected to be weaker at higher temperatures. It seems that this effect offsets the impact of the increased capture cross-sections. Moreover, this effect is more dominant when there is a strong band bending (larger $\Psi_{s}$ ) due to a large $Q_{f}$, thus, the temperaturedependence of $n_{s}$ and $p_{s}$ are stronger. It is noticeable that the contribution of the larger capture cross-sections at increasing temperatures to the overall surface recombination is relatively strong at the low-temperature range, for wafers with low $Q_{f}$.

The difference between $\tau_{\text {eff }}$ and $\tau_{s}$ (shown in Fig. 7) is assumed to be due to $\tau_{\text {bulk }}$. Fig. 8 presents $\tau_{b u l k}$ extracted by subtracting the simulated $\tau_{s}$ from measured $\tau_{\text {eff. }}$. The good agreement between the extracted value, as indicated by the tight distribution, confirms our model as it appears the developed model provides a good fit for four wafers across a wide range of both $\Delta n$ and temperature.

Table I summarizes the interface defects' parameters obtained in this study and compares them to reported values. The attained $Q_{f}$ is lower compared to other studies $\left(6 \times 10^{10}\right.$ $3 \times 10^{11} \mathrm{q} / \mathrm{cm}^{2}$ ). This could be due to the difference in the oxidation process. It has been suggested that $Q_{f}$ reduces with increasing oxidation temperature [71]. The obtained $D_{i t \_m g}$ is 
within the reported range for cases with and without FGA treatment. It is important to note that $D_{i t} m g$ is strongly impacted by the fabrication process, including the cleaning and the post oxidation steps. For example, the $D_{i t \_m g}$ reported by Aberle $e t$ al. [23] is much lower due to the additional post-metallization annealing process.

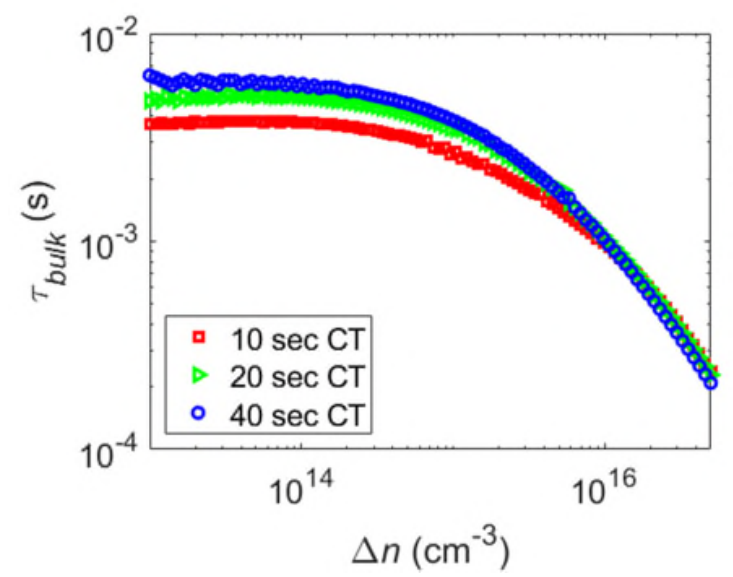

Fig. 8. Extracted injection dependent $\tau_{\text {bulk }}$ at $303 \mathrm{~K}$ for corona charged wafers with different CT (a) $10 \mathrm{sec}$ (b) $20 \mathrm{sec}$ and (c) $40 \mathrm{sec}$.

The reported capture cross-section from literature has a wide range. Albohn et al. [68] found that the large $\sigma_{n}(\mathrm{E})$ can be assigned to the $\mathrm{P}_{\mathrm{b}}$ centre, which originates from silicon dangling bonds with three back-bonded silicon atoms, while the $\mathrm{P}_{\mathrm{L}}$ defect that originates from silicon dangling bonds where one back-bond is substituted by oxygen, is commonly dominated by a lower $\sigma_{n}(\mathrm{E})$. Our values are within the expected range, although, we hope this study reduces the uncertainty range and provides a temperature dependency that has not been reported previously.

\section{CONCLUSIONS}

In this work, we have employed temperature-dependent photoconductance decay measurements to study $\mathrm{Si}_{-} \mathrm{SiO}_{2}$ interface electrical properties. We observed a $\tau_{\text {eff }}$ improvement at elevated temperatures. However, high temperatures are also found to be detrimental to hydrogen-passivated dangling bonds, as well as the stability of corona charge.

A modelling method is presented to determine the interface defects' parameters by temperature- and injection-dependent $\tau_{\text {eff }}$ measurements. This method reduces the uncertainty associated with the extracted interface defects' parameters since the fitting was performed for a large set of data taken at different temperatures and $\Delta n$.

$Q_{f}$ and $D_{i t}$ mg are determined to be $(1 \pm 0.5) \times 10^{10} \mathrm{q} / \mathrm{cm}^{2}$ and $(1.3 \pm 0.2) \times 10^{11} \mathrm{~cm}^{-2} \mathrm{eV}^{-1}$, respectively, for the $\mathrm{Si}-\mathrm{SiO}_{2}$ interface. FGA effectively reduces $D_{i t \_m g}$ to $(4.5 \pm 1) \times 10^{10} \mathrm{~cm}^{-2} \mathrm{eV}^{-1}$. Importantly, the temperature-dependent capture cross-sections are determined as $(2 \pm 0.4) \times 10^{-16} \exp \left[(-10 \pm 1) \times 10^{-3} / \mathrm{kT}\right]$ and
$(1 \pm 0.4) \times 10^{-16} \exp \left[(-10 \pm 1) \times 10^{-3} / \mathrm{kT}\right] \quad \mathrm{cm}^{2}$ for electrons and holes, respectively. The suggested lattice relaxation multiphonon emission capture process has a relatively large impact on the surface passivation at the lower temperature range when a low amount of $Q_{f}$ is present in the dielectric. However, for large $Q_{f}$, the temperature-dependence of surface recombination is found to be strongly influenced by carrier concentration at the surface and by their temperature-dependence. This study also highlights the need for a temperature-dependent intrinsic recombination model that will allow even deeper understanding regarding the temperature dependence of the surface recombination at high injection.

It was concluded that the $\mathrm{SiO}_{2}$ layer is expected to benefit from high operational temperatures, possibly yielding some advantages to the overall device performance in the field. The obtained results are expected to be valuable for improving the understanding regarding surface recombination in realistic operating conditions, as well as temperature-dependent device modelling for predicting and optimizing solar cell performance beyond STC.

\section{ACKNOWLEDGEMENT}

This work was supported by the Australian Government through Australian Renewable Energy Agency [ARENA; project 2017/RND001] and the Australian Centre for Advanced Photovoltaics (ACAP). The views expressed herein are not necessarily the views of the Australian Government, and the Australian Government does not accept responsibility for any information or advice contained herein. R. S. Bonilla is a recipient of a Royal Academy of Engineering Research Fellowship and acknowledges the support from EPSRC Postdoctoral Fellowship EP/M022196/1.

\section{APPENDIX A}

Figure A1 shows the fitting residual map obtained from fitting the temperature and injection dependent $\tau_{\text {eff }}$ for the wafer passivated with only $\mathrm{SiO}_{2}$ (as discussed in Section III-B). It seems that the residual is lower when both $Q_{f}$ and $\sigma_{n 0}$ are low. The optimal fit can be identified by the lowest residual (marked by a red star with a residual of 0.3). Since the residuals of all the other $Q_{f}$ and $\sigma_{n 0}$ combinations are higher, we can determine that within the map's resolution the obtained fit is unique. 


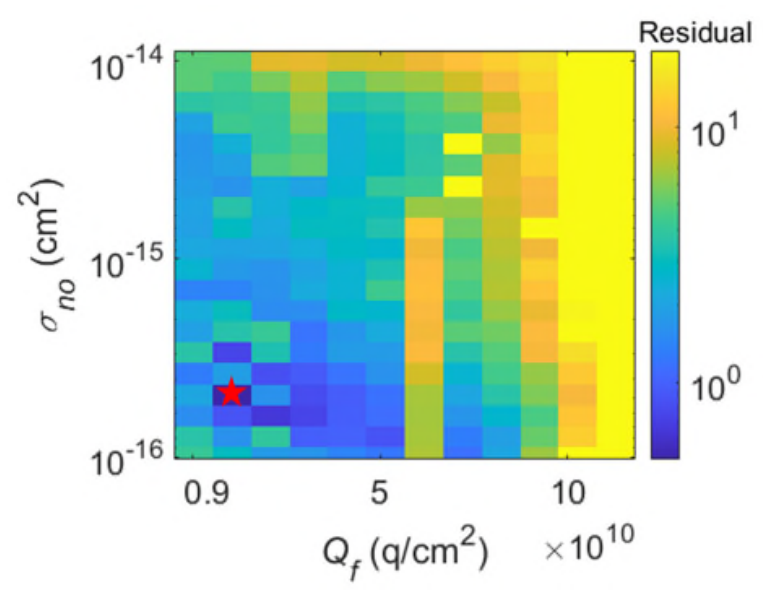

Fig A1. Fitting residual map obtained by fitting the temperature and injection dependent $\tau_{\text {eff }}$ for the wafer passivated with only $\mathrm{SiO}_{2}$. Red star indicates the minimum of this residual map.

\section{REFERENCES}

[1] M. Green, Solar cells: operating principles, technology, and system applications, Prentice-Hall, Englewood Cliffs, 1982.

[2] Y.M. Yang, A. Yu, B. Hsu, W.C. Hsu, A. Yang, C.W. Lan, Development of high-performance multicrystalline silicon for photovoltaic industry, Prog. Photovoltaics Res. Appl. 23 (2015) 340-351. https://doi.org/10.1002/pip.

[3] M.B. Shabani, T. Yamasbita, E. Marita, Study of gettering mechanisms in silicon: Competitive gettering between phosphorus diffusion gettering and other gettering sites, Solid State Phenom. 131-133 (2007) 399-404. https://doi.org/10.4028/www.scientific.net/ssp.131-133.399.

[4] B.J. Hallam, P.G. Hamer, A.M. Ciesla née Wenham, C.E. Chan, B.V. Stefani, S. Wenham, Development of advanced hydrogenation processes for silicon solar cells via an improved understanding of the behaviour of hydrogen in silicon, Prog. Photovoltaics Res. Appl. 28 (2020) 12171238. https://doi.org/10.1002/pip.3240.

[5] C. Battaglia, A. Cuevas, S. De Wolf, High-efficiency crystalline silicon solar cells: Status and perspectives, Energy Environ. Sci. $\quad 9 \quad$ (2016) 1552-1576. https://doi.org/10.1039/c5ee03380b.

[6] ITRPV, International technology roadmap for photovoltaic, Itrpv. (2019) 1-76. https://itrpv.vdma.org/en/ueber-uns.

[7] R.S. Bonilla, B. Hoex, P. Hamer, P.R. Wilshaw, Dielectric surface passivation for silicon solar cells: A review, Phys. Status Solidi Appl. Mater. Sci. 214 (2017) 1700293-1-30. https://doi.org/10.1002/pssa.201700293.

[8] A.G. Aberle, Crystalline silicon solar cells : advanced surface passivation and analysis, Centre for Photovoltaic Engineering, University of New South Wales, 1999.

[9] A. Cuevas, D. Yan, Misconceptions and misnomers in solar cells, IEEE J. Photovoltaics. 3 (2013) 916-923. https://doi.org/10.1109/JPHOTOV.2013.2238289.
[10] A. Cuevas, T. Allen, J. Bullock, Y. Wan, D. Yan, X. Zhang, Skin care for healthy silicon solar cells, 2015 IEEE 42nd Photovolt. Spec. Conf. (2015) 1-6. https://doi.org/10.1109/PVSC.2015.7356379.

[11] S.W. Glunz, F. Feldmann, $\mathrm{SiO}_{2}$ surface passivation layers - a key technology for silicon solar cells, Sol. Energy Mater. Sol. Cells. $\quad 185 \quad$ (2018) 260-269. https://doi.org/10.1016/j.solmat.2018.04.029.

[12] A.G. Aberle, Surface passivation of crystalline silicon solar cells: a review, Prog. Photovoltaics Res. Appl. 8 (2000) 473487. https://doi.org/10.1002/1099159X(200009/10)8:5<473::AID-PIP337>3.0.CO;2-D.

[13] R. Hezel, R. Schörner, Plasma Si nitride-A promising dielectric to achieve high-quality silicon MIS/IL solar cells, J. Appl. Phys. 52 (1981) 3076-3079. https://doi.org/10.1063/1.329058.

[14] A.G. Aberle, Overview on $\mathrm{SiN}$ surface passivation of crystalline silicon solar cells, Sol. Energy Mater. Sol. Cells. 65 (2001) 239-248. https://doi.org/10.1016/S09270248(00)00099-4.

[15] G. Dingemans, W.M.M. Kessels, Status and prospects of $\mathrm{Al}_{2} \mathrm{O}_{3}$-based surface passivation schemes for silicon solar cells, J. Vac. Sci. Technol. A. 30 (2012) 0408021-26. https://doi.org/10.1116/1.4728205.

[16] W. Soppe, H. Rieffe, A. Weeber, Bulk and surface passivation of silicon solar cells accomplished by silicon nitride deposited on industrial scale by microwave PECVD, Prog. Photovoltaics Res. Appl. 13 (2005) 551-569. https://doi.org/10.1002/pip.611.

[17] S.M. Sze, K.K. Ng, Physics of semiconductor devices, Wiley, New York, 1981.

[18] E.H. Nicollian, J.R. Brews, MOS (Metal Oxide Semiconductor) Physics and Technology, Wiley, New York, 1982.

[19] W.D. Eades, R.M. Swanson, Determination of the capture cross section and degeneracy factor of $\mathrm{Si}-\mathrm{SiO}_{2}$ interface states, Appl. Phys. Lett. 44 (1984) 988-990. https://doi.org/10.1063/1.94622.

[20] W.D. Eades, R.M. Swanson, Improvements in the determination of interface state density using deep level transient spectroscopy, J. Appl. Phys. 56 (1984) 1744-1751. https://doi.org/10.1063/1.334179.

[21] T.J. Tredwell, C.R. Viswanathan, Determination of interfacestate parameters in a MOS capacitor by DLTS, Solid. State. Electron. $\quad 23 \quad(1980) \quad 1171-1178$. https://doi.org/10.1016/0038-1101(80)90029-5.

[22] E.H. Nicollian, A. Goetzberger, MOS conductance technique for measuring surface state parameters, Appl. Phys. Lett. 7 (1965) 216-219. https://doi.org/10.1063/1.1754385.

[23] A.G. Aberle, S.W. Glunz, A.W. Stephens, M.A. Green, Higheficiency silicon solar cells: $\mathrm{Si} / \mathrm{SiO}_{2}$, interface parameters and their impact on device performance, Prog. Photovoltaics Res. Appl. 2 (1994) 265-273. https://doi.org/10.1002/pip.4670020402. 
[24] W. Füssel, M. Schmidt, H. Angermann, G. Mende, H. Flietner, Defects at the $\mathrm{Si} / \mathrm{SiO}_{2}$ interface: Their nature and behaviour in technological processes and stress, Nucl. Instruments Methods Phys. Res. Sect. A Accel. Spectrometers, Detect. Assoc. Equip. 377 (1996) 177-183. https://doi.org/10.1016/0168-9002(96)00205-7.

[25] H. Deuling, E. Klausmann, A. Goetzberger, Interface states in $\mathrm{Si}_{-} \mathrm{SiO}_{2}$ interfaces, Solid. State. Electron. 15 (1972) 559571. https://doi.org/10.1016/0038-1101(72)90157-8.

[26] J. Snel, The doped $\mathrm{Si} / \mathrm{SiO}_{2}$ interface, Solid. State. Electron. 24 (1981) 135-139. https://doi.org/10.1016/00381101(81)90008-3.

[27] J.T. Ryan, A. Matsuda, J.P. Campbell, K.P. Cheung, Interface-state capture cross section-Why does it vary so much?, Appl. Phys. Lett. 106 (2015) 163503. https://doi.org/10.1063/1.4919100.

[28] R.B.M. Girisch, R.P. Mertens, R.F. De Keersmaecker, Determination of $\mathrm{Si}_{-} \mathrm{SiO}_{2}$ interface recombination parameters using a gate-controlled point-junction diode under illumination, IEEE Trans. Electron Devices. 35 (1988) 203222. https://doi.org/10.1109/16.2441.

[29] A.G. Aberle, S. Glunz, W. Warta, Impact of illumination level and oxide parameters on Shockley-Read-Hall recombination at the $\mathrm{Si}-\mathrm{SiO}_{2}$ interface, J. Appl. Phys. 71 (1992) 4422-4431. https://doi.org/10.1063/1.350782.

[30] M. Schofthaler, R. Brendel, G. Langguth, J.H. Werner, Highquality surface passivation by corona-charged oxides for semiconductor surface characterization, in: Proc. 1994 IEEE 1st World Conf. Photovolt. Energy Convers. - WCPEC (A Jt. Conf. PVSC, PVSEC PSEC), IEEE, 1994: pp. 1509-1512. https://doi.org/10.1109/WCPEC.1994.520237.

[31] J. Schmidt, A.G. Aberle, Easy-to-use surface passivation technique for bulk carrier lifetime measurements on silicon wafers, Prog. Photovoltaics Res. Appl. 6 (1998) 259-263. https://doi.org/10.1002/(SICI) 1099-

159X(199807/08)6:4<259::AID-PIP215>3.0.CO;2-Z.

[32] S.W. Glunz, D. Biro, S. Rein, W. Warta, Field-effect passivation of the $\mathrm{SiO}_{2}$-Si interface, J. Appl. Phys. 86 (1999) 683-691. https://doi.org/10.1063/1.370784.

[33] R.S. Bonilla, C. Reichel, M. Hermle, P. Hamer, P.R. Wilshaw, Long term stability of $\mathrm{c}-\mathrm{Si}$ surface passivation using corona charged $\mathrm{SiO}_{2}$, Appl. Surf. Sci. 412 (2017) 657667. https://doi.org/10.1016/j.apsusc.2017.03.204.

[34] C. Berthod, S.T. Kristensen, R. Strandberg, J.O. Odden, S. Nie, Z. Hameiri, T.O. Saetre, Temperature sensitivity of multicrystalline silicon solar cells, IEEE J. Photovoltaics. 9 (2019) 957-964. https://doi.org/10.1109/JPHOTOV.2019.2911871.

[35] S. Nie, S.T. Kristensen, A. Gu, T. Trupke, Z. Hameiri, A novel method for characterizing temperature sensitivity of silicon wafers and cells, in: 2019 IEEE 46th Photovolt. Spec. Conf., IEEE, 2019: pp. 0813-0816. https://doi.org/10.1109/PVSC40753.2019.8980725.

[36] S. Nie, S.T. Kristensen, A. Gu, R.L. Chin, T. Trupke, Z.
Hameiri, Photoluminescence-based spatially resolved temperature coefficient maps of silicon wafers and solar cells, IEEE J. Photovoltaics. $10 \quad$ (2020) 585-594. https://doi.org/10.1109/JPHOTOV.2019.2956261.

[37] S.T. Kristensen, S. Nie, C. Berthod, R. Strandberg, J.O. Odden, Z. Hameiri, Temperature coefficients of crystal defects in multicrystalline silicon wafers, IEEE J. Photovoltaics. $\quad 10 \quad$ (2020) 449-457. https://doi.org/10.1109/JPHOTOV.2020.2968111.

[38] R.S. Bonilla, P.R. Wilshaw, Stable field effect surface passivation of n-type Cz silicon, Energy Procedia. 38 (2013) 816-822. https://doi.org/10.1016/j.egypro.2013.07.351.

[39] N.E. Grant, V.P. Markevich, J. Mullins, A.R. Peaker, F. Rougieux, D. Macdonald, Thermal activation and deactivation of grown-in defects limiting the lifetime of floatzone silicon, Phys. Status Solidi - Rapid Res. Lett. 10 (2016) 443-447. https://doi.org/10.1002/pssr.201600080.

[40] Y. Zhu, Z. Hameiri, Review of injection dependent charge carrier lifetime spectroscopy, Prog. Energy. (2020). https://doi.org/10.1088/2516-1083/abd488.

[41] R.A. Sinton, A. Cuevas, M. Stuckings, Quasi-steady-state photoconductance, a new method for solar cell material and device characterization, in: Conf. Rec. Twenty Fifth IEEE Photovolt. Spec. Conf., IEEE, 1996: pp. 457-460. https://doi.org/10.1109/PVSC.1996.564042.

[42] D.B.M. Klaassen, A unified mobility model for device simulation-II. Temperature dependence of carrier mobility and lifetime, Solid. State. Electron. 35 (1992) 961-967. https://doi.org/10.1016/0038-1101(92)90326-8.

[43] A.S. Grove, D.J. Fitzgerald, Surface effects on p-n junctions: Characteristics of surface space-charge regions under nonequilibrium conditions, Solid. State. Electron. 9 (1966) 783806. https://doi.org/10.1016/0038-1101(66)90118-3.

[44] R.S. Bonilla, P.R. Wilshaw, On the $\mathrm{c}-\mathrm{Si} / \mathrm{SiO}_{2}$ interface recombination parameters from photo-conductance decay measurements, J. Appl. Phys. 121 (2017) 135301. https://doi.org/10.1063/1.4979722.

[45] R. Couderc, M. Amara, M. Lemiti, Reassessment of the intrinsic carrier density temperature dependence in crystalline silicon, J. Appl. Phys. 115 (2014) 093705. https://doi.org/10.1063/1.4867776.

[46] R.G. Humphreys, Valence band averages in silicon: Anisotropy and non-parabolicity, J. Phys. C Solid State Phys. 14 (1981) 2935-2942. https://doi.org/10.1088/00223719/14/21/011.

[47] M.A. Green, Intrinsic concentration, effective densities of states, and effective mass in silicon, J. Appl. Phys. 67 (1990) 2944-2954. https://doi.org/10.1063/1.345414.

[48] A. Richter, S.W. Glunz, F. Werner, J. Schmidt, A. Cuevas, Improved quantitative description of Auger recombination in crystalline silicon, Phys. Rev. B. 86 (2012) 165202. https://doi.org/10.1103/PhysRevB.86.165202.

[49] T. Trupke, M.A. Green, P. Würfel, P.P. Altermatt, A. Wang, J. Zhao, R. Corkish, Temperature dependence of the radiative 
recombination coefficient of intrinsic crystalline silicon, J. $\begin{array}{lllll}\text { Appl. } & \text { Phys. } & 94 & \text { (2003) } & \end{array}$ https://doi.org/10.1063/1.1610231.

[50] P.P. Altermatt, F. Geelhaar, T. Trupke, X. Dai, A. Neisser, E. Daub, Injection dependence of spontaneous radiative recombination in c-Si: experiment, theoretical analysis, and simulation, in: Proc. 5th Int. Conf. Numer. Simul. Optoelectron. Devices, IEEE, 2005: pp. 47-48. https://doi.org/10.1109/NUSOD.2005.1518128.

[51] W. Shockley, W.T. Read, Statistics of the Recombinations of Holes and Electrons, Phys. Rev. 87 (1952) 835-842. https://doi.org/10.1103/PhysRev.87.835.

[52] R.N. Hall, Electron-Hole Recombination in Germanium, Phys. Rev. $87 \quad$ (1952) 387-387. https://doi.org/10.1103/PhysRev.87.387.

[53] Z. Xin, S. Duttagupta, M. Tang, Z. Qiu, B. Liao, A.G. Aberle, R. Stangl, An improved methodology for extracting the interface defect density of passivated silicon solar cells, IEEE J. Photovoltaics. 6 (2016) 1080-1089. https://doi.org/10.1109/JPHOTOV.2016.2576685.

[54] J.A. Cooper, R.J. Schwartz, Electrical characteristics of the $\mathrm{SiO}_{2}-\mathrm{Si}$ interface near midgap and in weak inversion, Solid. State. Electron. $17 \quad$ (1974) 641-654. https://doi.org/10.1016/0038-1101(74)90086-0.

[55] M. Schulz, N.M. Johnson, Evidence for multiphonon emission from interface states in MOS structures, Solid State Commun. 25 (1978) 481-484. https://doi.org/10.1016/00381098(78)90162-X.

[56] H. Haug, S. Olibet, Ø. Nordseth, E. Stensrud Marstein, Modulating the field-effect passivation at the $\mathrm{SiO}_{2} / \mathrm{c}-\mathrm{Si}$ interface: Analysis and verification of the photoluminescence imaging under applied bias method, J. Appl. Phys. 114 (2013) 174502. https://doi.org/10.1063/1.4827417.

[57] L.E. Black, K.R. McIntosh, Modeling recombination at the $\mathrm{Si}-\mathrm{Al}_{2} \mathrm{O}_{3}$ interface, IEEE J. Photovoltaics. 3 (2013) 936-943. https://doi.org/10.1109/JPHOTOV.2013.2247464.

[58] C.H. Henry, D. V. Lang, Nonradiative capture and recombination by multiphonon emission in GaAs and GaP, Phys. Rev. B. 15 (1977) 989-1016. https://doi.org/10.1103/PhysRevB.15.989.

[59] S. Wang, D. Macdonald, Temperature dependence of Auger recombination in highly injected crystalline silicon, J. Appl. Phys. 112 (2012) 113708. https://doi.org/10.1063/1.4768900.

[60] T. Niewelt, A. Richter, T.C. Kho, N.E. Grant, R.S. Bonilla, B. Steinhauser, J.-I. Polzin, F. Feldmann, M. Hermle, J.D. Murphy, S.P. Phang, W. Kwapil, M.C. Schubert, Taking monocrystalline silicon to the ultimate lifetime limit, Sol. Energy Mater. Sol. Cells. 185 (2018) 252-259. https://doi.org/10.1016/j.solmat.2018.05.040.

[61] S. Rein, Lifetime spectroscopy a method of defect characterization in silicon for photovoltaic applications, 2005.

[62] R.S. Bonilla, F. Woodcock, P.R. Wilshaw, Very low surface recombination velocity in $\mathrm{n}$-type c-Si using extrinsic field effect passivation, J. Appl. Phys. 116 (2014) 054102. https://doi.org/10.1063/1.4892099.

[63] R.S. Bonilla, I. Al-Dhahir, M. Yu, P. Hamer, P.P. Altermatt, Charge fluctuations at the $\mathrm{Si}-\mathrm{SiO}_{2}$ interface and its effect on surface recombination in solar cells, Sol. Energy Mater. Sol. $\begin{array}{llll}\text { Cells. } & 215 & \text { (2020) }\end{array}$ https://doi.org/10.1016/j.solmat.2020.110649.

[64] A. Goetzberger, E. Klausmann, M.J. Schulz, Interface states on semiconductor/insulator surfaces, Crit. Rev. Solid State $\begin{array}{llll}\text { Sci. } & 6 & \text { (1976) } & 1-43 .\end{array}$ https://doi.org/10.1080/10408437608243548.

[65] K.R. McIntosh, R.A. Sinton, Uncertainty in photoconductance lifetime measurements that use an inductive-coil detector, in: Proc. 23rd Eur. Photovolt. Sol. Energy Conf., 2008: pp. 77-82. https://doi.org/10.4229/23rdEUPVSEC2008-1AO.6.2.

[66] F.J. Himpsel, F.R. McFeely, A. Taleb-Ibrahimi, J.A. Yarmoff, G. Hollinger, Microscopic structure of the $\mathrm{SiO}_{2} / \mathrm{Si}$ interface, Phys. Rev. B. 38 (1988) 6084-6096. https://doi.org/10.1103/PhysRevB.38.6084.

[67] M.L. Reed, J.D. Plummer, Chemistry of $\mathrm{Si}_{-} \mathrm{SiO}_{2}$ interface trap annealing, J. Appl. Phys. 63 (1988) 5776-5793. https://doi.org/10.1063/1.340317.

[68] J. Albohn, W. Füssel, N.D. Sinh, K. Kliefoth, W. Fuhs, Capture cross sections of defect states at the $\mathrm{Si} / \mathrm{SiO}_{2}$ interface, J. Appl. Phys. 88 (2000) 842-849. https://doi.org/10.1063/1.373746.

[69] R.S. Bonilla, N. Jennison, D. Clayton-Warwick, K.A. Collett, L. Rands, P.R. Wilshaw, Corona charge in $\mathrm{SiO}_{2}$ : kinetics and surface passivation for high efficiency silicon solar cells, Energy Procedia. $92 \quad$ (2016) 326-335. https://doi.org/10.1016/j.egypro.2016.07.090.

[70] S. Choi, J. Baek, T. Kim, K.H. Min, M.S. Jeong, H. Song, M.G. Kang, D. Kim, Y. Kang, H. Lee, J. Myoung, S. Park, Interface analysis of ultrathin $\mathrm{SiO}_{2}$ layers between c-Si substrates and phosphorus-doped poly-Si by theoretical surface potential analysis using the injection-dependent lifetime, Prog. Photovoltaics Res. Appl. 29 (2021) 32-46. https://doi.org/10.1002/pip.3338.

[71] B.E. Deal, M. Sklar, A.S. Grove, E.H. Snow, Characteristics of the Surface-State Charge (Qss) of Thermally Oxidized Silicon, J. Electrochem. Soc. 114 (1967) 266-273. https://doi.org/10.1149/1.2426565. 